\title{
A educación en valores na Institución Libre de Ensinanza en España: ética e estética
}

\section{Values education in the Institución Libre de Ensinanza in Spain: ethics and aesthetics}

\author{
María Eugenia BOLAÑO AMIGO \\ Universidade de Santiago de Compostela
}

\begin{abstract}
RESUMO: A Institución Libre de Ensinanza, movemento de renovación pedagóxica que maior pegada deixou sentir no contexto español do século XX, outorgou á ética un valor educativo preeminente. Na base da educación en valores que a ILE procurou encóntrase a estética, cultivada de forma primordial mediante o coidado da natureza, as excursións, a educación física, os traballos manuais e a ensinanza artística e musical.
\end{abstract}

PALABRAS CHAVE: Institución Libre de Ensinanza, educación en valores, ética, estética, moral.

ABSTRACT: The Institución Libre de Ensinanza, educational reform movement that had higger influences in twentieth century Spanish context, gave ethics a prominent educational value. On the base of values education that ILE sought is aesthetics, so primordial cultivated by care of nature, excursions, physical education, crafts and artistic and musical education.

KEYWORDS: Institución Libre de Ensinanza- Values Education- Ethics- Aesthetics- Moral.

\section{Introdución}

A educación é un acto intencional e, polo tanto, necesariamente axiolóxico que require dun compromiso ético e moral, traducido en valores asumidos a partir dunha profunda reflexión e inevitablemente transmitidos dun modo máis ou menos explícito. Estes valores son o substrato de todas as nosas accións, polo que é inevitable recoñecer a súa importancia na e para a praxe educativa.

Tomamos este punto de partida como suposto desde o que sinalar que probablemente un dos episodios máis destacados da historia da educación en valores en España aconteceu no devir da Institución Libre de Ensinanza (en adiante ILE) ao longo de seis décadas. Esta institución, como é coñecido, foi fundada no ano 1876 por parte de varios catedráticos e auxiliares de universidade e de instituto separados do seu exercicio docente a consecuencia da súa protesta contra os decretos de instrución pública de 1875 impostos 
desde unha orientación política conservadora que penalizaba a liberdade de cátedra. A ela incorporaríanse desde os primeiros momentos outros intelectuais e membros dos corpos políticos liberais e republicanos que non estaban dispostos a asumir os imperativos monárquicos e católicos da chamada Restauración. 0 seu sustento progresista, como ben sinala Vilafranca Manguán ${ }^{1}$, tornouse o seo alternativo en que medraron os proxectos pedagóxicos renovadores da Restauración española (1876-1931), perdurando como tal ata o comezo da guerra civil (1936) e influenciando a política da Segunda República (1931-1939).

A ética e a moral en que se fundamentan os valores dos que partía a ILE para 0 desenvolvemento dos procesos educativos -a través tanto da propia institución creada en Madrid, como da incidencia e irradiación que logrará mediante o Boletín de la Institución Libre de Enseñanza, que será examinado mensualmente nos catro puntos cardinais do territorio hispano-, estaban arraigadas no discurso liberal institucionista, asentado á súa volta na atmosfera do krausismo². A filosofía krausista, introducida en España por Julián Sanz del Río (tendo como discípulo máis destacado a Francisco Giner de los Ríos) alimentou, coa creación da ILE, un movemento educativo e de renovación cultural que procuraba a reforma da sociedade española. Cun discurso que se manifestaba contrario ante calquera dogmatismo, a traxectoria pedagóxica da ILE configurouse, no panorama peninsular contemporáneo, como unha das máis importantes en prol da secularización, con todas as consecuencias educativas que isto supón.

No substrato desta educación ética institucionista encóntrase a estética ${ }^{3}$, cultivada especialmente co coidado da natureza, as excursións, a educación física, os traballos manuais e a ensinanza artística e musical que practicaban, na procura primordial do desenvolvemento do espírito crítico e da creatividade (aspectos mediante os que se poden constatar as influencias do naturalismo rousoniano e pestalozziano) e outorgando sempre

\footnotetext{
${ }^{1}$ Isabel Vilafranca Manguán, "La Institución Libre de Enseñanza: una educación moral para la tolerancia", en Historia de la Educación en Valores. Volumen II, coord. Vilanou y Collelldemont, (Bilbao: Desclée de Brower, 2001), 195-208.

${ }^{2}$ Nesta liña convén citar a alusión que Herminio Barreiro fai a que tamén "o trasfondo da inspiración dos primeiros homes da Institución -os compañeiros de Giner- viña determinado por unha certa concepción do mundo neoilustrada, moi próxima á ideoloxía e práctica política e profesional da masonería europea" (Barreiro, 2001:14); Herminio Barreiro Rodríguez, "A Institución Libre de Enseñanza, unha política da Pedagoxía", Sarmiento. Anuario Galego de Historia da Educación, no 5 (2001), 7-21. Sobre as orientacións ideolóxicas europeas e a súa incidencia en España e na ILE pode mencionarse a primeira parte do traballo de Natividad I. Ortega Morales, La educación estética en la Institución Libre de Enseñanza (Almería: Servicio de Publicaciones Universidad de Almería, 2000). ${ }^{3}$ Dun modo específico, en relación coa educación estética na Institución Libre de Ensinanza elaborou a súa tese de doutoramento Natividad I. Ortega Morales, La Educación Estética en la Institución Libre de Enseñanza. Tamén pode destacarse a contribución de José A. Garrido González e Amparo Pinto Martín, "La educación estética en la Institución Libre de Enseñanza", Revista Interuniversitaria de Formación del Profesorado, 27 (1996), 151-166, onde se salientan as dificultades que entraña ofrecer unha reconstrución ao respecto debido á escaseza de fontes que se aproximen directamente á devandita temática, entre as que mencionan o artigo de José Giner Pantoja, "La Educación Estética en la Institución", en En el Centenario de la Institución Libre de Enseñanza, VV.AA. (Madrid: Tecnos, 1977), 51-56, e algúns apartados en obras dedicadas á ILE e a Manuel Bartolomé Cossío, figura que acompañou máis directamente a Giner de los Ríos. Non obstante, constatamos que existen múltiples achegas relativas á dimensión estética do krausismo das que nalgunha medida daremos conta.
} 
moita importancia á cultura e ás artes populares ${ }^{4}$. Unhas prácticas tales asentadas na educación integral ${ }^{5}$ e representadas nas actuacións dos seus intelectuais máis representativos, Francisco Giner de los Ríos (1839-1915) e Manuel Bartolomé Cossío (1857-1935), que debuxaron un panorama certamente estimulante, chegando a favorecer o posterior desenvolvemento do movemento da Escola Nova.

\section{Unha ética e unha moral asentadas no krausismo ${ }^{6}$}

O discurso ético e moral da ILE deriva da súa procedencia filosófica krausista, e incluso pode dicirse que a súa "cosmovisión descansa nas formulacións de Krause e de Julián Sanz del Río"'. O krausismo é, máis que unha escola filosófica, un think tank que parte do pensamento do filósofo alemán Krause (1781-1832), discípulo de Schelling e de Fichte, logrando unha importante difusión especialmente en Bélxica, en España e en Sudamérica.

A filosofía krausista, que fora xa inicialmente exposta por Ramón de la Sagra ${ }^{8}$, chega a terras españolas sobre todo da man de Sanz del Río (1814-1869), quen estuda e traduce as obras de Krause á lingua castelá. Neste contexto adquirirá un protagonismo que

\footnotetext{
${ }^{4}$ Aludindo á cuestión da relevancia que a pedagoxía institucionista outorgaba á cultura popular e ás artes tradicionais e, polo tanto, ligadas aos contextos máis próximos, podemos sinalar os seus precedentes na Estética de Krause, nas ideas que os prerrafaelistas e o movemento que Ruskin desencadean en Inglaterra, así como no influxo que a irrupción das ideas de Bauhaus tiveron na ILE xa no século XX (Eugenio Otero Urtaza, "El proyecto institucionista de educación popular", en La Institución Libre de Enseñanza y Francisco Giner de los Ríos: nuevas perspectivas. 2 La institución Libre de Enseñanza y la cultura española, (Madrid, Fundación Francisco Giner de los Ríos/Acción Cultural Española, 2013: 594-611).

${ }^{5}$ Comprendendo que neste contexto do século XIX se asumía como tal a tríade configurada pola educación física, a moral e a intelectual.

${ }^{6}$ Queremos destacar que comprendemos aquí a ética (do grego ethos: carácter, modo de ser; vertido ao latín como mos-moris, costume, moral) na súa utilización dominante actual, derivada das formulacións anglosaxoas que a comprenden como a "ciencia dos principios da moral, sendo a moral a aplicación concreta destes principios nas accións humanas. $O$ presuposto necesario da ética é a afirmación da liberdade humana, ou sexa, a idea de que a existencia do home é modificable por propia vontade e que a súa conduta se encontra inevitablemente afectada por un deber ser dunha maneira e non deber ser doutra (...) tanto no persoal como no colectivo (...); ao longo da Historia déronse diversas explicacións para concretar ese deber e ese criterio fundamental" (Diego Sánchez Meca, Diccionario de Filosofía, Madrid: Alderabán, 1996:174-175).Cabe dicir que hoxe se considera a Sócrates o fundador da ética, "en canto que se preocupou de buscar unha orientación radical á vida. A diferenza dos saberes teóricos, a ética constitúe un tipo de saber que orienta a acción humana nun sentido racional" (Feliciano Blázquez, Diccionario de las Ciencias Humanas, Navarra: Verbo Divino, 1997:157).

Unha completa revisión bibliográfica en relación ao krausismo e a ILE é a elaborada por Eugenio Otero Urtaza, "Bibliografía sobre krausismo e Institución Libre de Enseñanza", en La Institución Libre de Enseñanza y Francisco Giner de los Ríos: nuevas perspectivas. 3 Antología de textos. Madrid, (Fundación Francisco Giner de los Ríos/ Acción Cultural Española, 2013:43-69).

${ }^{7}$ Luis Palacio Bañuelos, "El mundo de los valores en la Institución Libre de Enseñanza", en Boletín de la Real Academia de Córdoba, no 116 (1989), 37.

${ }^{8}$ Antón Costa Rico, "Ramón de la Sagra: Reforma social y escolar. Sus visitas a escuelas infantiles y primarias (Bélgica, Holanda y Alemania, 1838-1843)", en La Constitución de Cádiz, genealogía y desarrollo del sistema educativo liberal/XII Coloquio Nacional de Historia de la Educación (Cádiz, 2013); Antón Costa Rico, "Sociedad burguesa y educación en el siglo XIX: la perspectiva reformista transnacional de Ramón de la Sagra y la educación en España", Bordón. Revista de Pedagogía, vol. 65, 4 (2013),47-60.
} 


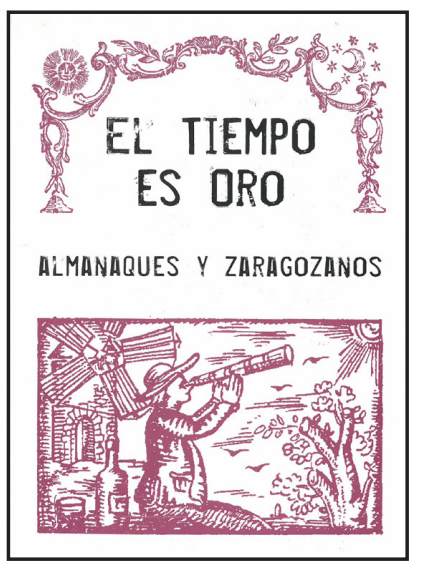

non acadara no seu país de orixe, converténdose nunha "filosofía que, aplicada á práctica polos krausistas españois, vai resultar ser esencialmente unha filosofía da liberdade (...); un renacemento ético que tivo o seu máximo representante en Giner de los Ríos" ${ }^{\prime \prime}$, que aparece impregnado dun marcado ton de protesta, configurando todo un estilo de vida que cre na perfectibilidade do ser humano, no progreso da sociedade e na beleza esencial da vida ${ }^{10}$.

Como xa indicamos, as bases institucionistas son asinadas 0 10 de marzo do ano 1876 en Madrid, e a Institución inaugúrase no mes de outubro dese mesmo ano. Desde aquela irradiará o seu modo de actuar e trasladará o seu pensamento á acción das persoas que a visitan ou xeran a súa formación nas súas aulas. A partir deste momento inicial, pode falarse de catro momentos ou etapas na historia da ILE: etapa universitaria (1876-1881), etapa de expansión (1881-1907), etapa de máxima influencia (1907-1918) e etapa final (de coexistencia con outras teorías educativas innovadoras, $1918-1936)^{11}$.

Ao longo destas etapas, na institución desenvolveranse prácticas pedagóxicas de base fröbeliana, tamén levadas a cabo por outras escolas innovadoras nesta época como foron a École Modèle de Bruselas, a École Alsacienne de París, o Pädagogium de Viena ou o King Alfred School de Londres; e, como destaca o profesor Otero Urtaza' ${ }^{12}$, a escola creada por Giner en Madrid era xa apreciada por prestixiosos educadores europeos. Así, no ano 1882, Henriette Schrader-Breymann (sobriña de Fröebel) transmitía a Cossío que a ILE era o movemento que mellor interpretaba o sentido do Kindergarten en Europa e, en 1884 The Times dicía que a ILE era a única escola continental que trataba de emular a educación inglesa mediante os principios de sobriedade mental, liberdade persoal e desenvolvemento físico a través dos xogos ao aire libre, que acostumaban ao autogoberno desde os primeiros días escolares. Así mesmo, salientaban no devandito xornal o feito de que a institución fose a escola que máis practicase o excursionismo de toda Europa ${ }^{13}$.

Por outra parte, o desexo de evitar toda doutrina relixiosa e dogmática deixou medrar na ILE "un discurso ideolóxico a favor da tolerancia. Esta imparcialidade xerou un foco de fricción co catolicismo conservador, o cal comportaría co paso do tempo máis dun conflito e controversia"14. Así, baixo este discurso de tolerancia e de liberdade que se propón na

\footnotetext{
${ }^{9}$ Luis Pañacio Bañuelos (1989), ibid., 38.

${ }^{10}$ Elena M. Jongh Rossel, El Krausismo y la generación de 1898 (Valencia: Albatros Ediciones, 1985).

${ }^{11}$ Julio Ruiz Berrio et al. (ed.), Un educador para un pueblo. Manuel B. Cossío y la renovación pedagógica institucionista (Madrid: UNED, 1987).

${ }^{12}$ Eugenio Otero Urtaza, Manuel Bartolomé Cossío: pensamiento pedagógico y acción educativa (Madrid: Centro de Publicaciones del Ministerio de Educación y Ciencia, 1994).

${ }^{13} \mathrm{lbid}$.

${ }^{14}$ Isabel Vilafranca Manguán (2001), ibid., 195.
} 
ILE pretendíase formar a persoa como valor fundamental, en relación co que Palacio Bañuelos (1989: 43) recolle do propio pensamento de Giner:

o que España necesita e debe pedir á escola non é precisamente homes que saiban escribir; o que necesita son 'homes', e formalos require educar o corpo tanto como o espírito, e a vontade, tanto ou máis que o entendemento. A conciencia do deber, o espírito de iniciativa, a confianza en si propio, a individualidade, o carácter, e xuntamente con isto a restauración do organismo corporal, tan decaído por causa da falta de hixiene, do exceso de traballo e a insuficiencia de alimentación: tal debe ser, naquilo que corresponde aos seus medios, o obxectivo da escola nova. ${ }^{15}$

Desta maneira, a tolerancia é asumida na ILE fundamentalmente como respecto e comprensión aos demais. Aludindo a este valor, aprecia Giner que

precisamente se hai unha educación relixiosa que deba darse na escola é esa da tolerancia positiva, non escéptica e indiferente; da simpatía cara a todos os cultos e crenzas, considerados como formas xa rudimentarias, xa superiores e aínda sublimes como o cristianismo, pero encamiñadas todas a satisfacer sen dúbida en moi diverso grao (...), segundo a súa cultura e demais condicións, unha tendencia inmortal do espírito humano. ${ }^{16}$

E, de igual modo, atendendo á propia definición do valor de liberdade que se desexa impulsar na Institución, Giner matiza que "a liberdade (...) é aquela calidade, inherente á actividade dun ser de razón, de determinarse a obrar por si mesmo, sendo el só causa dos seus actos e podendo facerse superior, na súa íntima e propia esfera, a todas as influencias exteriores"17; nesta interpretación pode percibirse a influencia dos "Mandamentos Ideais e prohibitivos" tomados do ideario de Krause ${ }^{18}$.

Ademais da tolerancia (que é, como se dixo, comprensión e respecto mutuo) e da liberdade (e daquela, a autonomía), os institucionistas pronúncianse en favor dos valores da

austeridade e da convivencia, na procura de harmonía ${ }^{19}$ e, o que é aínda máis importante, actúan en consonancia. Exemplo disto é a importancia moral que outorgaban aos premios e castigos, que consideraban debían ser sinxelos e de valor psicolóxico, nunca de tipo físico, avogando pola capacidade de autonomía do individuo na loita pola autosatisfacción do deber ético cumprido. A educación da vontade e do carácter (que non deixa de ser educación moral) é unha das dimensións ás que Giner dedica máis páxinas, negando todo o que represente violencia e coerción, e afirmando que non se forma ao neno impedindo a súa acción con prohibicións, senón procurando que sexa el quen decida.

A ILE soubo expresar e transmitir estes e outros valores non menos transcendentes a través dunha ética conformada tamén por unha educación estética que asumiu un papel crucial. Cremos, en afinidade co pensamento de Giner e doutros institucionistas, que

\footnotetext{
${ }^{15}$ Giner de los Ríos, 1900:243; cit. en Palacio Bañuelos, 1989, ibid., 43.

${ }^{16}$ Giner de los Ríos; cit. en Laporta, 1977, ibid., 152.

${ }^{17}$ Giner de los Ríos, 1884:109; cit. en Palacio Bañuelos, 1989, ibid., 43.

${ }^{18}$ Os que se ven recollidos na obra de Krause, Ideal de la humanidad para la vida, obra que, nas súas edicións primeira (1860) e segunda (1871), posúe introdución e comentarios de Sanz del Río. Sobre esta cuestión podemos consultar Aullón de Haro, Krause. Compendio de estética, traducido del alemán y anotado por Francisco Giner (Madrid: Verbum, 2009).

${ }^{19}$ Luis Palacios Bañuelos, 1989, ibid., 44.
} 
non pode existir educación estética sen educación en valores (dun modo máis ou menos implícito ou explícito), e tamén que a educación en valores que non xoga coa educación estética perde un ámbito esencial de expresión e transmisión. Neste sentido, hai que dicir que a ILE aproveitou esta potencialidade ética da estética, sendo esta unha das súas múltiples dimensións de referencia que abordamos na epígrafe seguinte.

\section{A educación en valores a través da educación estética na Institución Libre de Enseñanza}

Os valores que se pretendían suscitar coa educación institucionista eran promovidos mediante as diversas prácticas pedagóxicas exercitadas, entre as que nos centraremos neste texto naquelas vinculadas á educación estética debido á importancia que,consideramos posúen para a educación ética e moral. En todo caso, antes de presentar esta cuestión requírese realizar unha delimitación conceptual do constructo "educación estética", xa que existen certas ambigüidades derivadas dos seus usos e consecuentes reformulacións discursivas ao longo da historia que poden dificultar a súa comprensión no sentido con que neste escrito a apreciamos. Deste modo, en primeiro lugar, procederemos a delimitar o que comprendían os institucionistas por "educación estética" e o que nós asumimos como tal, para logo poder ofrecer un percorrido polas prácticas pedagóxicas desenvolvidas na Institución a través das cales se evidencia esta educación en valores presente na educación estética.

\section{Delimitación conceptual: un percorrido pola noción de educación estética e os seus fundamentos na ILE}

A estética é un campo de traballo común no ámbito da filosofía sobre o que se levan pronunciado de forma destacada autores como Baumgarten, Kant, Hume, Hegel, Adorno e Heidegger. Etimoloxicamente o termo "estética" procede do grego aisthêticos, que se refire a aquilo que os sentidos poden percibir, remitindo á "facultade de sentir", á "comprensión polos sentidos" e á "percepción totalizante". Acudindo ao Dicionario de Filosofía de Sánchez Meca (1996) podemos achegar que esta acepción foi empregada por Baumgarten no século XVIII para aludir ao estudo da sensación, á ciencia da percepción sensible, aspecto en que Kant incidiu ao falar da "estética trascendental"20. Posteriormente, a estética constituíuse en ciencia do fermoso e do sentimento que produce en nós, estudando aquí, en particular, os problemas da creación de obras de arte e os relativos á súa percepción e valoración ${ }^{21}$. A estética contemporánea "diversificou as súas orientacións, dirixíndose ao estudo das formas no seu desenvolvemento histórico, á análise das relacións entre unha obra e 0 artista que a crea, á determinación da relación entre arte e a sociedade etc"22.

\footnotetext{
${ }^{20}$ Beardsley Monroe \& Hospers, Estética. Historia y fundamentos (Madrid: Cátedra, 1990).

${ }^{21}$ Cuestións fundamentadas por Kant na súa Crítica do xuízo, onde proxecta a idea dunha finalidade interna como a meta específica das obras de arte, afirmación que Hegel rebateu, destacando, pola súa parte, a necesidade do esclarecemento do significado da arte co estudo da súa historia para facer intelixible esa finalidade.

${ }^{22}$ Diego Sánchez Meca, 1996, ibid.,171-172.
} 
A historia da estética na cultura occidental, rigorosamente falando, podería dicirse que comeza da man do filósofo alemán Alexander G. Baumgarten no século XVIII (introdutor deste termo na súa obra Reflexiones filosóficas acerca de la poesía, [Meditationes philosophicae de nonnullis ad poema pertinentibus] que data do ano 1753) e, sobre todo, coa sistematización desta disciplina realizada por Kant; pero a súa acepción remite a estudos efectuados por filósofos anteriores e especialmente, ao igual que a súa propia etimoloxía, ao mundo clásico grego. Podería sinalarse, pois, que en Grecia naceu a estética como concepto, mentres que con Baumgarten se converteu nunha ciencia filosófica.

Do mesmo xeito, a educación estética estivo sempre presente no discurso de todos os filósofos e pedagogos no transcurso da historia da educación, sendo Platón o primeiro filósofo que aborda este tema en profundidade (principalmente no seu décimo libro da República), seguido por Aristóteles e, xa na Idade Media, por santo Agostiño e san Tomé. No século XVII será Comenio na súa Didáctica Magna quen defenderá a necesidade do ensino das artes na escola, pero é no século XVIII con Schiller (mediante as súas cartas dedicadas á educación estética) cando nace a necesidade de estimular este tipo de formación, ao considerar que non existe unha auténtica educación se o home non recibe unha educación estética (Oriol de Alarcón, 2005) 23. $^{23}$

O concepto de "educación estética" asumiuse, polo tanto, desde moi diversas perspectivas, segundo Clément, Demonque, Hansen-Love e Kahn (2000)24: como estudo da sensación e do sentimento, como teoría da arte e das condicións do belo e como teoría que trata do sentimento do belo e do xuízo do gusto, entre outras. Por extensión, vénse considerando en múltiples ocasións á educación estética como sinónimo da educación artística, pero aquí queremos facer fincapé en que ambas difiren na súa definición e que, en todo caso, poderá aceptarse que esta última se inclúe no campo da educación estética. Somos conscientes de que a educación artística é un contraforte fundamental para 0 desenvolvemento da sensibilidade estética, pero non por iso ambos os conceptos poden verse subsumidos.

Mediante a revisión dalgúns autorizados dicionarios de pedagoxía podemos constatar as disparidades na delimitación de ambos os conceptos ("educación estética" e "educación artística"), que nalgúns casos se ven solapados (como acontece no Diccionario de Pedagogía dirixido por Sánchez Sarto, 1936); noutros son configurados como sinónimos (o que pode apreciarse na definición do Diccionario de Ciencias de la Educación coordinado por Prellezo García, 2009, e tamén no Diccionario Enciclopédico de Educación dirixido por

\footnotetext{
${ }^{23}$ Nicolás Oriol de Alarcón, "Educación estética y artística", en Pedagogía y educación ante el siglo XXI, ed. Ruiz Berrio (Madrid: Departamento de Teoría e Historia de la Educación de la Universidad Complutense de Madrid, 2005). Cómpre tamén consultar Givone. Historia de la estética (Madrid: Tecnos, 2001).

${ }^{24}$ Clément, Demonque, Hansen-Love \& Kahn, La philosophie de A à Z (París: Hatier, 2000).
} 
Martí Castro, 2002); mentres que noutras ocasións si queda esta diferenciación establecida, aínda que non sempre dun modo esclarecedor e prudente. No Dicionario Galego de Pedagoxía ${ }^{25}$ distínguese entre ambos os conceptos (os dous definidos por Mesías Lema e Agra Pardiñas): a "educación estética" exponse como "unha acción dinámica, transversal e formativa dentro da Educación das Artes Visuais, que ten como finalidade o desenvolvemento intelectual e persoal da apreciación dos valores estéticos presentes nos artefactos e obxectos artísticos que están no noso contorno máis próximo" e a "educación artística", neste caso, compréndese como unha mera "materia encargada de xerar conexións e producir cuestións entre a arte e a educación, cuxo campo de coñecemento se centra nos procesos de aprendizaxe artística que desenvolven os alumnos"; sen pretender xerar controversia ao respecto, cremos que ambas as acepcións non poden ser tan vagamente consideradas e que, en xeral, son os dicionarios de filosofía os que mellor se achegan a estas definicións.

Valoramos que a educación estética é, en concordancia coa definición de Garrido González e Pinto Martín'26: "aquela que ten por obxecto, por un lado, cultivar a sensibilidade para a apreciación da beleza e a arte, e para desenvolver nalgunha medida o espírito de creación e expresión artísticas; por outro, [pretende] educar na persoa un sentido estético da vida". Como postula Luzuriaga ${ }^{27}$, "se quixésemos sintetizar nunha frase o obxectivo da educación estética poderiamos dicir que o seu fin é a formación do bo gusto". Con esta última consideración xa Read ${ }^{28}$ considerou a educación estética como "a educación deses sentidos sobre os cales se basea a conciencia e, en última instancia, a intelixencia e 0 xuízo humano". Este mesmo autor observou como percepción e imaxinación se conxugan nas actitudes psíquicas da persoa que desenvolve a experiencia estética, facendo que as sensacións e os sentimentos afloren e se interrelacionen, unha experiencia que pode suscitarse a partir da comprensión e da apreciación dos valores inherentes á propia vida, contribuíndo, polo tanto, á construción do pensamento e da forma de ollar e sentir o mundo que nos envolve.

Seguindo esta liña pode retomarse o pensamento do filósofo e pedagogo alemán Eduard Spranger (1882-1963) ${ }^{29}$ en relación cos valores ${ }^{30}$ ao entendelos dunha forma dinámica, ligados ás estruturas culturais ao longo da historia, sendo, deste xeito, captados

\footnotetext{
${ }^{25}$ José A. Caride e Felipe Trillo, Dicionario Galego de Pedagoxía (Vigo: Galaxia, 2010).

${ }^{26}$ José A. Garrido González e Amparo Pinto Martín, 1996, ibid., 152.

${ }^{27}$ Lorenzo Luzuriaga, La Institución Libre de Enseñanza y la educación en España (Buenos Aires: Universidad, 1981), 142

${ }^{28}$ Herbert Read, La educación por el arte (Barcelona: Paidós, 1982), 59-60.

${ }^{29}$ Definido brevemente por Vázquez-Prada Oñoro (1967: 5) como "filósofo culturalista que,propugnando unha pedagoxía humanística e da personalidade, se inclina, sen embargo, cara un idealismo místico". O pensamento de Spranger (que foi profesor en Leipzig, Berlín e Tubinga) constitúe unha síntese da filosofía clásica, do idealismo e das achegas de Dilthey.

${ }^{30}$ Debido á incidencia que este autor posúe, ao respecto, no pensamento posterior e polas matizacións krausistas idealistas que no seu pensamento poden atoparse.
} 
e transformados polo ser humano. Este discípulo de Wilhelm Dilthey ${ }^{31}$ considerou o "eu" como un todo estruturado ao redor dun valor dominante en cada individuo, en función do que se sitúan os restantes valores baixo unha pauta determinada (Vázquez-Prada Oñoro, 1967) ${ }^{32}$; o predominio duns valores determinados (a saber: estético, económico, político, social, relixioso ou teorético) derivaría en diferentes formas de vida ${ }^{33}$. Spranger propuxo como método de aprendizaxe un estudo "comprensivo" da cultura, dos valores que inspiran cada forma de cultura historicamente dada, e considerou que os valores estéticos procuran a harmonía desde unha visión subxectiva do mundo afirmada mediante a experimentación.

Cremos que esta visión, xunto coas ideas do crítico de arte John Ruskin (1819-1900)34, poden vincularse á visión da "estética" e da "educación estética" institucionista, pois ambas as perspectivas interligadas poden atoparse no pensamento e nas prácticas institucionistas, dun modo especial na estética krausista, que pode quedar resumida na seguinte afirmación do seu fundador: "verdade, bondade e beleza son completamente conformes e irmás entre si, constituíndo como o acorde fundamental na harmonía da esencia e a vida" 35 , así como nas reflexións de Giner (quen foi introdutor da estética de Krause en España a través da tradución do seu Compendio de Estética) e de Cossío.

Podemos sinalar que a concepción estética de Ruskin influenciou dunha forma particular o pensamento de Cossío, grande admirador deste ${ }^{36}$. Destaca no ideario do crítico de arte inglés que un dos temas principais dos seus escritos é a relación entre a arte e a moral (temática que trata orixinalmente no seu primeiro volume de Pintores Modernos, 1843); tamén é salientable no seu pensamento a relevancia que outorga ao instinto e á emoción, ao amor e ao desexo. Ademais, cómpre distinguir que Ruskin cre que o impulso da beleza se debe moldear xustamente no hábito de ver. Este poder outorgado á visión, á imaxinación e á interpretación que propón Ruskin, é firmemente acreditado polos institucionistas e,

\footnotetext{
${ }^{31}$ Dilthey (1833-1911), de orixe alemá, foi un filósofo, historiador, sociólogo, psicólogo e estudoso da hermenéutica. Ao longo da súa traxectoria como profesor de filosofía nas universidades de Basilea, Kiel, Breslau e Berlín, afirmou que o estudo das ciencias humanas supón a interacción entre a experiencia persoal, o entendemento reflexivo da experiencia e unha expresión do espírito nos xestos, palabras e arte, recalcando que todo coñecemento, para que non sexa parcial, debe ser analizado á luz da historia.

${ }^{32} \mathrm{M}^{\mathrm{a}}$ Teresa Vázquez-Prada Oñoro, El pensamiento pedagógico de Eduardo Spranger (Barcelona: Universidad de Barcelona, 1967).

${ }^{33}$ Atendendo a esta temática pode salientarse a súa obra: Formas de vida: psicología y ética de la personalidad (1914, primeira edición en castelán). Neste autor destacan as influencias dos principais autores do século de ouro alemán: Goethe, Kant, Pestalozzi, Herbart, Humbolt e Schleiermacher.

${ }^{34} \mathrm{O}$ londinense John Ruskin foi o principal crítico de arte inglés da época vitoriana, tamén mecenas da arte, debuxante, acuarelista, sociólogo e escritor. Escribiu a súa primeira obra na defensa do paisaxismo de Turner. Máis tarde, o seu esteticismo moral, relacionado directamente co idealismo de Th. Carlyle, levaríao a reaccionar contra o materialismo, denunciando os perigos da industrialización, aproximándose ao socialismo e ás novas utopías sobre planificación urbana, e asociando a reflexión artística coas iniciativas prácticas e as disquisicións morais. $\mathrm{O}$ acceso a este autor, ao igual que a outras diversas fontes, foime moi amablemente sinalado polo profesor Dr. Otero Urtaza.

${ }^{35}$ Krause, Ideal de la humanidad para la vida (Madrid: Imprenta de Martínez García, 1870), 1358-1359.

${ }^{36}$ Eugenio Otero Urtaza, 1994, ibid.
} 
dun modo especial, por Cossío $0^{37}$. A preocupación por ensinar a ver, contemplar, admirar e a interpretar supón, segundo os institucionistas, desenvolver o carácter e a sensibilidade, espertar o gusto por crear un mesmo, suscitar unha predisposición que poida propiciar 0 ollar crítico requirido na vida e, fundamentalmente, gozar coa aprendizaxe.

Neste senso, Pinilla Burgos (2005) ${ }^{38}$ expón que se atendemos ás ideas da estética institucionista, pode comprobarse como algunhas das cuestións máis características deste aspecto se atopan abordadas noutras obras de Krause como son o Compendio de estéti$\mathrm{ca}^{39}$, o Sistema de la Filosofía e o Ideal de la Humanidad para la vida, ambos os textos tamén traducidos e editados por Sanz del Río. Baixo esta influencia krausista, Giner alude á concepción estética escribindo que "o ideal estético desenvolverá no mundo unha función máis importante do que adoita crerse; e o gusto, indefinida denominación deste sentido, debe considerarse por todos os homes reflexivos como unha das primeiras potencias dinámicas da vida social". ${ }^{40}$

Partindo do exposto nos parágrafos anteriores, destacamos como a educación estética entronca directamente coa educación en valores, xa que supón a reflexión e a interpretación sobre a realidade e os valores que nela se configuran. Constatamos, tamén, que unha revisión das concepcións actuais referidas á educación estética e á educación artística podería ser interesante, nun momento en que as propias concepcións hexemónicas sobre a arte se esvaecen. Como podemos apreciar, o discurso sobre o que xira o pensamento estético institucionista non dista do que nós comprendemos como tal e, indo máis alá, chega a ser asumido como a mediación fundamental entre o ser humano e a súa historia.

\section{Prácticas pedagóxicas na ILE asentadas nunha educación estética transmisora de valores}

A exaltación da arte e da cultura (compoñentes esenciais da noción de estética) como elementos educativos, foron as dimensións educativas cultivadas na ILE que chegarán a ser algunhas das súas máis orixinais achegas, pois constituíron no seu tempo unha novidade dentro das concepcións curriculares do ensino europe ${ }^{41}$.

\footnotetext{
${ }^{37}$ Quen dedica a esta temática o artigo El arte de saber ver no ano 1879 (Eugenio Otero Urtaza, "La educación infantil en la Institución Libre de Enseñanza", en Historia y perspectiva actual de la educación infantil, coord. Sanchidrián y Ruiz Berrio (Barcelona: Graó, 2010).

${ }^{38}$ Ricardo Pinilla Burgos, El pensamiento estético de Krause (Madrid: Universidad Pontificia de Comillas, 2005). De Pinilla Burgos podemos destacar, ademais, o seu traballo: Francisco Giner de los Ríos como traductor y receptor de la estética de Krause. En Álvarez Lázaro e Vázquez Romero, Krause, Giner y la Institución Libre de Enseñanza. Nuevos estudios (Madrid: Publicaciones de la Universidad Pontificia de Comillas, 2000).

${ }^{39}$ Krause, Compendio de estética, traducido del alemán y anotado por Franciso Giner, edición de Pedro AUllón de Haro, $2^{a}$ edición (Madrid: Verbum, 2009).

${ }^{40}$ Giner, cit. en Natividad I. Ortega Morales, 2001, ibid., 345.

${ }^{41}$ José A. Garrido González e Amparo Pinto Martín, 1996, ibid.; Natividad I. Ortega Morales, La enseñanzaaprendizaje del arte: una innovación educativa de la Institución Libre de Enseñanza (Granada: Grupo Editorial Universitario, 2002, 392); María Rosario Caballero, Inicios de la historia del arte en España: la Institución Libre de Enseñanza (1876-1936) (Madrid, CSIC, Instituto de Historia, Departamento de Historia del Arte, 2003).
} 
Sentimento, intuición, creatividade, imaxinación e espírito crítico toman protagonismo coa educación estética; sendo a partir dela desde onde se forma nos valores da tolerancia, o respecto mutuo, a comprensión, a liberdade, a autonomía, o rigor, a austeridade e a convivencia. A educación artística, eido no que Cossío amosará unha particular implicación, adquire por todo 0 sinalado na ILE un alcance singular para o fomento da sensibilidade estética. Neste sentido convén indicar que, ademais de educador, Cossío foi un extraordinario crítico de arte. De feito, da súa autoría é a Historia de la pintura española e El Greco, libro que lle outorgou recoñecemento a nivel internaciona ${ }^{42}$.

En relación coa educación artística, cabe sinalar tamén que os institucionistas eran sabedores da estimulación do "pensamento diverxente" 43 a partir do bo ensino das artes, potenciando a apertura para a creatividade, a innovación e a sensibilidade, sen desmerecer nunca a información que enriquece a disciplina mental ${ }^{44}$.

Máis alá do sinalado, na exaltación da arte e da cultura nun camiño de cara a propiciar o talante estético, toma relevancia a promoción das artes populares:

os bordados, os traxes e sombreiros, os cacharros de barro, que expresaban a idiosincrasia e temperamento dun pobo ${ }^{45}$ (aínda que) Cossío non cría que a obra da educación remataba cando o neno sabía ver e facer, ou sabía xulgar o valor das cousas: ser educado implicaba ter capacidade de gozar coa beleza, de ser sensible ante o que o mundo nos mostra e logramos construír como persoas vivas, xa que, como afirmaba con frecuencia, a educación vivifica; e cría que a vida humana en plenitude era en si mesma unha obra artística, cuxa raíz se atopa na acción. ${ }^{46}$

A educación estética impregna, pois, o currículo institucionista desde os tres anos de idade nos que comezan os estudos ${ }^{47}$ ata os dezaoito, nun único ciclo sen solución de continuidade e cun corpo único de ensinantes especializados por idades (unha proposta de universalización do ensino altamente anovadora). Ao longo dun plan de estudos en que a educación primaria e secundaria conforman un continuum, o programa inclúe, alén das materias tradicionais, antropoloxía, tecnoloxía, ciencias sociais, economía, arte, debuxo,

\footnotetext{
${ }^{42}$ Eugenio Otero Urtaza, 2007, ibid.

${ }^{43}$ Empregamos aquí este concepto como xenericamente equivalente ao de "pensamento creativo", sendo sabedores de que o concepto "pensamento diverxente" non foi empregado até 0 ano 1951, cando o psicólogo norteamericano Joy Guilford clasificou o pensamento en dúas clases: converxente e diverxente, aludindo ao segundo como aquel tendente ao emprego da imaxinación, buscando solucións e alternativas inconformistas, polo que se relaciona directamente co concepto de creatividade.

${ }^{44}$ Isto poderemos aprecialo a través de: Cossío, El maestro, la escuela y el material de enseñanza y otros escritos (Madrid: Biblioteca Nueva, 2007); Giner de los Ríos, Ensayos menores sobre educación y enseñanza. Tomo XVIII (Madrid: La lectura, 1927); Giner de los Ríos, Obras completas, vol. XIII, 169 (Madrid: Espasa-Calpe,1933); Giner de los Ríos, Las artes y las letras y otros ensayos. (Sevilla: Clásicos andaluces, 2007), entre outros.

${ }^{45} \mathrm{~A}$ isto se refire no seu "Elogio del arte popular", reprodución do prólogo de: Bordados populares y encajes, Exposición de Madrid, mayo de 1913. En: La Colección Jiménez-Cossío del Museo das Mariñas. Betanzos: Museo das Mariñas, 1996.

${ }^{46}$ Otero Urtaza, 2010, ibid, 172.

${ }^{47}$ En atención ao que se debe sinalar que "o aspecto máis innovador da ILE en relación coa educación de párvulos foi o descubrimento da importancia dos sentimentos estéticos" (Otero Urtaza, 2010:171). Sobre o saber ver e o saber facer, así como sobre a arte e o desenvolvemento dos sentimentos estéticos na infancia destaca 0 traballo de E. Otero Urtaza, "La Educación infantil en la Institución Libre de Enseñanza", en Historia y perspectiva actual de la educación infantil, coord. Sanchidrián e Ruiz Berrio (Barcelona: Graó, 2010).
} 
canto e labores; contidos desenvolvidos nunhas clases articuladas a través do diálogo socrático e de métodos intuitivos, nunha conversa informal e familiar. Conversas entre alumnado e profesorado que se trasladaban ás prácticas pedagóxicas máis innovadoras executadas pola ILE, nas que a educación en valores e a educación estética impregnaban toda a actuación, porque 0 desenvolvemento da sensibilidade estética se esperta a partir do contacto coa realidade, coa natureza e cos obxectos de creación humana.

Entre as devanditas prácticas aludiremos neste escrito polo interese que gardan en relación coa temática que tratamos: as excursións e visitas (nomeadamente, destacan as visitas a museos e a espazos arquitectónicos), a práctica deportiva, a música e o traballo manual. En todas estas propostas pódese apreciar a educación activa, social, física, intelectual e, por suposto, ética, moral e estética. Conscientes de que cada unha delas requiriría dun tratamento moito máis amplo e profundo, tan só pretendemos achegarnos aquí puntualmente aos centros de interese que nos concirnen.

\section{A educación estética e os valores a través das excursións e visitas}

As excursións, colonias escolares e visitas ${ }^{48}$ son apreciadas na ILE como 0 medio de ensino e aprendizaxe por excelencia. Mediante estas valiosas prácticas educativas os institucionistas visitan diversas rexións españolas, parte de Francia e de Portugal. 0 coñecemento da natureza e da cultura, a valoración da paisaxe e da creación humana, son os obxectivos primordiais destes desprazamentos, en que se tentaba manter 0 ambiente familiar do ensino, cunha comunicación fluída entre todos, polo que sempre evitaban a masificación tendente á excesiva planificación das actividades.

Nas excursións salienta o feito de que non se explicaba anticipadamente aos nenos o que ían ver e coñecer, senón que tiñan que ser eles mesmos os que descubrisen e destacasen aquilo que lles parecera relevante, aspecto que está fortemente vinculado á educación estética e aos valores. Así, os nenos desenvolven autonomía, a autoconfianza e un pensamento crítico dificilmente conseguido doutra maneira. Ademais, os hábitos de saúde e hixiene, respecto e admiración á natureza, son fundamentais nestas viaxes de aprendizaxe.

Coas visitas, principalmente realizadas a museos e a espazos arquitectónicos, a educación artística asume un rol crucial. Nelas é indispensable facilitar aos individuos o desenvolvemento da súa creatividade no contacto co traballo artístico, con obras xa creadas intencionalmente polo home: as propiamente artísticas. A preocupación estética de Giner (que nos fala do espertar da crítica artística na infancia no seu artigo "La crítica espontánea de los niños en Bellas Artes", BILE, 9, 1885, 41-42) e dos institucionistas non podía relegar a importancia da educación artística, á que Cossío destinou moitas das súas palabras.

\footnotetext{
${ }^{48}$ Para afondar nesta temática debe consultarse: E. Otero Urtaza, "Aproximación a la práctica excursionista de la Institución Libre de Enseñanza", en Education, Physical activities and Sport in a historical perspective. International Standig conference for the History of Education, ed. Jordi Monés i Pere Solà., (Catalunya: Secretaría General de Deporte, 1992), 205-209.
} 
Coas indagacións producidas a partir destas viaxes de educación estética é o alumno quen escribe o seu propio libro de texto, o que é reflexo da forte procura do razoamento crítico fronte á mera memorización. Tratábase de que os nenos coñecesen mediante a experiencia a natureza e algunhas das máis altas manifestacións belas da arte (que non necesariamente son aquelas que se atopan nos museos e, así, fan fincapé na importancia da cultura popular e do cotiá) para aprender a valoralas e a extraer as súas propias conclusións.

O papel do mestre nestas actividades era primordial, xa que:

como artista da educación non só desenvolvía as destrezas do bo pensar, senón que tamén lle descubría ao neno as belas emocións do vivir, a paixón dos sentidos que levan o home a intimar coa súa natureza e lle posibilita a apertura cara aos semellantes. A contemplación de obras de arte e o saber ler nelas os camiños que tiña emprendido a humanidade constitúe un aspecto central nesta educación e aparécesenos como o trazo máis persoal da súa acción educadora. ${ }^{49}$

Os institucionistas estaban convencidos de que os xogos ao aire libre e as excursións non só formaban, como ningún outro medio, o carácter moral do alumnado, senón que tamén os liberaban do exceso de "intelectualismo" das aulas. No programa definitivo da ILE pode lerse unha moi apaixonada defensa da súa práctica; del pode extraerse que os fins estéticos do excursionismo e das visitas son moi manifestos, escapando ás consideracións de instrución e saúde corporal. Así, gozar coa natureza e a arte, abrir os sentidos ao mundo, non xa para coñecer e comprender, senón para gozar, é unha cuestión moi ben definida no seu ideario pedagóxico50; "para eles, o esforzo, sempre que non producise dor ou malhumor, contiña un valor crucial para a formación da xuventude, e cando se resolvía nun pracer 'san' posuía unha enorme riqueza educativa". ${ }^{51}$

\section{A educación estética e os valores mediante a práctica deportiva}

$O$ deporte, que adquire unha notable presenza coa práctica excursionista e coas coIonias escolares, configúrase como un elemento clave das relacións entre o corpo e 0 espírito ${ }^{52}$. As condicións hixiénicas, tanto dos locais como do alumnado, as propias regras e actuacións deportivas, e o traballo en equipo, entre outros aspectos, requiren dun forte rigor e honestidade. Os valores promovidos coa educación física poden inducirse tendo en conta as preferencias polo xogo e o paseo no campo en troques da práctica ximnástica.

Cossío consideraba que o ensino "non era outra cousa que activar a función reflexiva, na que incluía a formación do carácter e da vontade. Aspectos que están na cerna das actividades físicas que se desenvolvían na ILE; porque activaban calidades máis intanxibles,

\footnotetext{
${ }^{49}$ Natividad I. Ortega Morales, 2000, ibid., 352.

${ }^{50}$ Otero Urtaza, "Aproximación a la práctica excursionista de la Institución Libre de Enseñanza", Education, Physical activities and Sport in a historical perspective. International Standig conference for the History of Education, en Jordi Monés i Pere Solà (Catalunya: Secretaría General de Deporte, 1992), 205-209.

${ }^{51} \mathrm{lbid}, 208$.

${ }^{52}$ En relación con esta cuestión pode consultarse: López Serra e Fernández Losa, "La educación física en la I.L.E.", en Revista de Educación. La educación en España en el siglo XX (Ministerio de Educación, Cultura y Deporte, 2000).
} 
e así atoparon pronto que xogos deportivos ao aire libre e excursións descubrían a idiosincrasia de cada alumno e deixaban unha pegada persistente que ía pulindo os caracteres" (Otero Urtaza, 2007:29). Así, co deporte procúrase un antídoto contra a preguiza, estando moi presente na ocupación do ocio. Pode dicirse que neste eido a ILE tamén achega innovacións, posto que introduce os xogos ingleses, sendo Capper no ano 1882 o primeiro en ensinar a xogar ao fútbol aos alumnos da institución.

\section{A educación estética e os valores na música}

A ILE realizou unha verdadeira innovación educativa no noso país introducindo a música como materia da ensinanza xeral en todos os niveis, "o feito de que se incorporase así esta materia aos programas de ensino da ILE e que nunca desaparecese deles, a pesar das dificultades económicas dalgunhas etapas, demostra que Francisco Giner e os institucionistas en conxunto consideraban a música como unha materia fundamental que debía formar parte da cultura xeral de calquera home e de calquera cidadán"53. Ademais, destacaron os intereses institucionistas polas músicas populares, propiciando a súa recuperación e divulgación a través de prácticas educativas que en moitas ocasións entroncaban tamén cos saberes literarios ${ }^{54}$.

Convén destacar tamén que a ILE ofrecía aos seus alumnos veladas musicais e literario-musicais, programaba conferencias sobre historia e estética musical organizadas polo propio Giner ${ }^{55}$ (grande amante da música, á que destinou notable atención) non restrinxidas ao alumnado, e practicaba sesións de canto coral cos alumnos universitarios. Nas veladas, a música de cámara -apreciándoa especialmente pola práctica da arte en grupo que suscita- e o repertorio de lied alemán tiveron excepcional protagonismo, tomando como referentes compositores do rango de Haydn, Mozart, Beethoven ou Mendelssohn. Todo isto realizábase coa pretensión de propiciar a "formación da cultura e gusto musicais" (Cossío, 1890; cit. en Leticia Sánchez de Andrés, 2009: 251).

A idea estética institucionista vinculada á música pode expresarse dalgún modo nas seguintes afirmacións de Krause: "a música refírese así mesmo dunha forma mediata á nosa vida intelectual, pois cada pensamento e coñecemento produce unha determinada excitación afectiva, que expresa logo esteticamente a creación musical. Así é que a beleza desta arte ten tamén por necesidade carácter intelectual". ${ }^{56}$

Deste xeito, coa base esencial da estética krausista, os institucionistas cren nos valores morais e intelectuais transmitidos a través da práctica e coñecemento musical, e incluso

\footnotetext{
${ }^{53}$ Leticia Sánchez de Andrés, 2007, ibid., 256.

${ }^{54}$ Juan López-Morillas (comp.), Krausismo: estética y literatura (Barcelona: Lumen, 1990).

${ }^{55}$ Sobre o pensamento e a actividade musical de Francisco Giner de los Ríos e as iniciativas krausoinstitucionistas no ámbito da educación musical referimos aquí a Leticia Sánchez de Andrés, "El pensamiento y la actividad musical de Francisco Giner de los Ríos. Iniciativas krausoinstitucionistas en el ámbito de la educación musical (1869-1915)", en Francisco Giner de los Ríos. Actualidad de un pensador krausista, coord. Vázquez-Romero (Madrid: Marcial Pons, 2009).

${ }^{56}$ Krause, cit. en Leticia Sánchez de Andrés, 2009, ibid., 209.
} 
mediante a propia música, sendo fundamental o gozo na aprendizaxe. Unha aprendizaxe musical que se desenvolvía na ILE mediante dous procesos paralelos: un máis práctico a través da interpretación musical (esencialmente mediante o canto coral) e outro teórico mediante a teoría e historia da música (sempre sustentada en audicións e exemplificacións prácticas). Con esta dobre vía (práctica e teórica) eran estimuladas en plena harmonía para o ser humano a dimensión espiritual, a do gusto, a dos sentidos e a corporal.

Pode recalcarse agora que nas ampliacións de Giner da teoría e da historia da música de Krause (traballos musicolóxicos máis completos do último) ${ }^{57}$ destacan o sentimento e a afectividade como as dimensións máis cultivadas mediante a música. Alén do sinalado, a ILE cumpría un importante labor de divulgación da cultura musical, chegando incluso a estimular a composición de obras por parte de músicos españois.

\section{A educación estética e os valores a partir do traballo manual}

O traballo manual apréciase na ILE como un elemento máis da cultura xeral dos alumnos, comezando na primeira infancia e estendéndose ao longo da primeira e segunda ensinanza. Esta institución foi a primeira en introducir en España o traballo manual no ensino primario "e talvez unha das primeiras en Europa que o incluíu na secundaria por consideralo elemento indispensable, non só da educación técnica, senón dentro de certos límites, de toda educación racional humana" ${ }^{58}$

Os tipos de traballos practicados eran, sobre todo, o debuxo (sempre natural), a modelaxe, a construción de corpos xeométricos de cartón, as coleccións de minerais, os herbarios e os traballos prácticos en laboratorio químico, o que en parte recorda as propostas didácticas realizadas por Fröbel.

Estas actividades realizadas desde o suposto de que os mellores recursos eran os ideados por cada mestre e feitos polo alumnado, activaban o desenvolvemento do traballo manual, de modo tal que os libros de texto quedaban relegados na escola, cuestión que nos dá idea da elevada carga de valores transmitidos desta forma. A creatividade, a imaxinación, a sensibilidade, o coidado e a habituación son fortemente impulsadas deste xeito.

\section{Conclusións}

A educación en valores que impregnou todas e cada unha das actuacións desenvolvidas na ILE e, dun modo especial, a educación estética -fundamento da educación dos sentimentos, afectiva e emocional- adquiriu na ILE un singular lugar. Neste sentido, se temos en consideración a amplitude das actuacións institucionistas, tentar abranguer dun modo conciso a temática proposta neste traballo tórnase, máis alá do aquí expresado, unha tarefa dificultosa.

\footnotetext{
${ }^{57}$ Sobre a ampliación da estética musical de Krause pode citarse o texto consultado de Luis Pinilla Burgos (2005), íbid.

${ }^{58}$ Giner, 1993, íbid., 169.
} 
Cremos que a educación en valores (e como sustento necesario desta, a educación estética) é fundamental para propiciar a adquisición dunha educación integral. Por isto, os supostos educativos formulados pola ILE e o propio ideario institucionista, que superan aínda en innovación á propia vixencia, son hoxe moi desexables. Moitos dos principios configuradores da ética e moral "institucionista" influenciaron a defensa da escola pública máis recente, polo que a nosa débeda pedagóxica merece ser saldada mediante o recoñecemento aos seus representantes.

A educación estética sempre tivo no devir histórico das sociedades un certo cariz aristocrático, como exercicio de ocio e distintivo dos selectos e sendo privilexio de clases favorecidas. A ILE tentou derruír este muro levando a educación en valores e na estética ao pobo en xeral, partindo dos propios saberes e sensibilidades populares, non só mediante as accións pedagóxicas desenvolvidas desde a escola institucionista, senón (e quizás en maior medida) a través dos outros órganos e centros inspirados pola ILE, entre os que destacaron o Museo Pedagóxico Nacional, o BILE, a Junta para Ampliación de Estudios, o Instituto-Escola, a Extensión Universitaria e a Residencia de Estudantes. Iniciativas a partir das que pintores, escritores, críticos de arte, músicos e científicos, entre outros, participaron das ideas dun renovador panorama. O principio intuitivo que configurou a súa visión da educación integral non deixou á marxe o saber ver, gozar e xulgar no que foi educada toda unha xeración que deixará pegada no contexto español contemporáneo.

En coherencia co pensamento de Arruda Aranha consideramos que "não é um exagero dizer que a postura estética ajuda a evitar as formas petrificadas, rígidas e intransigentes, do moralismo ou do fanatismo político. Talvez porque (...) esteja na dimensão do 'sonho acordado', da utopia, que nada mais é do que a expressão da esperança" 59 . Explorar os sentidos (esencialmente "o aprender a ver" tan recomendado por Cossío, un ollar que acciona verdadeiramente todos os sentidos e capacidades das persoas), cultivar os sentimentos e a afectividade, abrirse á imaxinación, crear ou aceptar o desafío da intuición é só posible suscitando o interese e a sede de coñecemento no alumnado, para que poidan chegar a ser e exercer como persoas conscientes e críticas.

En definitiva, a ILE xerou unha experiencia educativa forte e de calidade da que todos nós somos debedores. Como ben sinalou o profesor Herminio Barreiro (2001) a Institución Libre de Ensinanza, na distancia, segue a ser un referente para todo o que se poida relacionar coa modernidade, coa renovación político-educativa e, en xeral, para todo 0 que teña algo que ver coa vangarda pedagóxica europea dos últimos cento trinta anos, de modo que, como el mesmo tamén mencionou, a historia contemporánea española ten moito que ver cos pasos desta institución educativa.

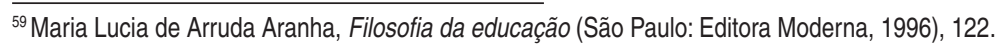

